\title{
EFEITOS DE RESTOS CULTURAIS DE MILHO NO DESENVOLVIMENTO INICIAL DE CAFEEIROS ${ }^{1}$
}

\section{EFFECTS OF CORN PLANT RESIDUES ON INITIAL DEVELOPMENT OF COFFEE PLANTS}

\author{
André Cabral FRANÇA ${ }^{2}$ \\ Itamar Ferreira de SOUZA ${ }^{3}$ \\ Luis Wagner Rodrigues ALVES 4 \\ Renato Ribeiro de LIMA \\ Eliane Queiroga de OLIVEIRA.
}

\begin{abstract}
RESUMO
A implantação da cultura de café em áreas plantadas com milho em anos anteriores tem mostrado efeitos negativos sobre o desenvolvimento das mudas transplantadas, provavelmente devido aos aleloquímicos do milho deixados no solo. Com o objetivo de identificar, em casa-de-vegetação, os efeitos que palhas de milho exercem sobre o crescimento inicial de plantas de café, foi instalado um experimento, na UFLA, Lavras - Minas Gerais. Os tratamentos foram constituídos de cultivares de café e incorporações de palhas de híbridos de milho colhidas em campo, no estádio 2, emissão do pendão. Efetuou-se a incorporação na proporção de $8 \mathrm{t} \mathrm{ha-1}$ de palha seca, em seguida plantou-se as mudas, sendo estas avaliadas aos 7, 30,60 e 90 dias após o plantio. 0 híbrido de milho GNZ 2004, quando incorporado, causou aumento de $18,76 \%$ na área foliar de plantas de café, em relação ao tratamento sem palha aos 90 DAP. O teor de clorofila e a biomassa seca do caule do cultivar de café Catucaí foram prejudicados pela palha do híbrido de milho GNZ2005, entretanto, o Topázio foi beneficiado pela palha do GNZ2004. A incorporação de palha dos híbridos GNZ2004 e P30K75 favoreceram o acúmulo de biomassa pelas raízes de plantas de café aos 90 DAP.
\end{abstract}

Palavras-chave: alelopatia; Zea mays; Coffea arabica.

\section{ABSTRACT}

Coffee crop planted to areas previously planted to corn have experienced negative effects on seedlings development, probably due to allelochemicals left in the soil by corn plants. With the objective of identifying the effects of corn straws on the initial growth and development of coffee seedlings, one greenhouse experiment was established at the Federal University of Lavras (UFLA), Lavras, MG, Brazil. The treatments were constituted by four coffee cultivars planted to pots filled with a mixture of field soil and five corn hybrid dried straws, harvested from field at flowering stage and incorporated at $8 \mathrm{t} \mathrm{ha}^{-1}$. Coffee seedlings growth parameters were measured at 7, 30, 60, and 90 days after planting (DAP). The GNZ 2004 corn hybrid straw promoted 18,76\% increase in coffee seedlings leaf area at 90 DAP when compared with control without straw. Chlorophyll content and stem dry matter of Catuaí coffee cultivar were inhibited by GNZ 2005 corn hybrid, however GNZ 2004 promoted increase in these parameters of Topázio cultivar. Straw incorporation of GNZ 2004 and P30K75 corn hybrids showed increase in roots dry matter accumulation of coffee seedlings at 90 DAP.

Key-words: allelopathy; Zea mays; Coffee arabica.

\footnotetext{
${ }^{1}$ Extraído da dissertação apresentada pelo autor à Universidade Federal de Lavras (UFLA), Cx. P. 37 - 37200-000 - Lavras, MG, para obtenção do título de mestre em Agronomia/Fitotecnia.

${ }^{2}$ Engenheiro Agrônomo, M.S em Agronomia/Fitotecnia, bolsista CNPq, Departamento de Agricultura (DAG - UFLA), Lavras (MG). Email: cabralfranca@yahoo.com.br, autor para correspondência.

${ }^{3}$ Engenheiro Agrônomo, Doutor em Agronomia, Professor Associado do Departamento de Agricultura, Universidade Federal de Lavras (DAG UFLA), Caixa Postal 37, Lavras - MG, E-mail: itamarfs@ufla.br

${ }^{4}$ Engenheiro Agrônomo, Doutor em Agronomia, Bolsista PROEX-UFLA, Departamento de Agricultura, Universidade Federal de Lavras, E- mail: luiswagner51@yahoo.com.br

${ }^{5}$ Zootecnista, Doutor Agronomia/Estatística e Experimentação agrícola, Professor do Departamento de Ciências Exatas, Universidade Federal de Lavras (DEX - UFLA), Caixa Postal 37, Lavras - MG, E-mail: rrlima@ufla.br

${ }^{6}$ Bióloga, Doutora em Agronomia/Fitotecnia, Departamento de Agricultura (DAG - UFLA), Lavras (MG). E-mail: eliqueiroga04@yahoo.com.br.
} 


\section{INTRODUÇÃO}

A cafeicultura é de grande importância econômica e social para o Brasil e, em especial, na região sul do estado de Minas Gerais, que apresenta uma imensa vocação para a cultura, constituindo a maior área plantada do país (AGRIANUAL, 2006).

Nesta região, após a abertura de áreas, temse implantado culturas anuais como um suporte econômico para a futura aquisição de mudas de café e fertilizantes (SANTOS, 2002). Outro benefício observado com a implantação destas culturas é para o aproveitamento dos restos culturais promovendo a reciclagem de nutrientes, suprimindo a emergência de plantas daninhas e evitando a erosão (PAES e ZITO, 2006).

Entretanto, os resíduos de muitas espécies interferem no desenvolvimento de outras, como é o caso de resíduos culturais de sorgo-guiné (Sorghum vulgare) interferindo no desenvolvimento da soja (OLIBONE et al., 2006); palhas de capim-braquiária (Brachiaria decumbens), que reduziram a síntese de clorofila de cultivares de café Mundo Novo e Icatu (SOUZA et al., 2000); resíduos de milho, quando incorporadas ao solo, afetaram o desenvolvimento de mudas de café cultivadas em sucessão (SANTOS et al., 2003; ALVES, 2003); restos culturais de milho causaram efeitos negativos sobre o trigo (GUENZI e McCALLA, 1966) e sobre o seu monocultivo (AL MEZORI et al., 1999). Observações de campo têm indicado que o estabelecimento inicial de cafeeiros vem sendo prejudicado pelos compostos alelopáticos liberados pela decomposição da palha do milho. Os restos desta cultura contem substâncias alelopáticas com propriedades reguladoras de crescimento prejudicando o desenvolvimento das plantas, sendo que a intensidade de tais efeitos depende do genótipo utilizado e de sua incorporação ou não ao solo (DURIGAN e ALMEIDA, 1993; FERREIRA e AQUILA, 2000). Esta interferência pode persistir por um período de até 22 semanas no solo (GUENZI \& McCALLA, 1966; AL MEZORI et al., 1999).

O efeito de palhas de milho sobre o desenvolvimento de mudas de café, foram avaliados por ALVES (2003) e SANTOS et al. (2003), tendo os autores concluído que existe efeito inibitório no desenvolvimento das mudas recém-transplantadas, e consideraram que o efeito é dependente do genótipo de milho plantado, podendo estimular ou reduzir o desenvolvimento.

Objetivou-se com este trabalho identificar, em casa-de-vegetação, os efeitos que palhas de milho exercem sobre o crescimento inicial de plantas de diferentes cultivares de cafeeiro.

\section{METODOLOGIA}

Um experimento foi conduzido em condições de casa-de-vegetação, no período de fevereiro a maio de 2006, no Centro de Ensino, Pesquisa e Extensão do Agronegócio do Café (CEPE-Café), da Universidade Federal de Lavras (UFLA), MG.

Utilizou-se o delineamento em blocos casualizados com quatro repetições, num esquema em parcela subdividida no tempo (BANZATTO e KRONKA, 2006). Os tratamentos foram dispostos em esquema fatorial $4 \times 5$, sendo os fatores: quatro cultivares de café, com característica de porte baixo (Catucaí - 2SL, Catuaí - IAC99, Rubi - MG1192 e Topázio - MG1190) e palhas incorporadas de cinco híbridos de milho mais plantados na região sul de Minas Gerais (GNZ2004, GNZ2005, P30K75, DKB350 e um tratamento sem palha, tido como testemunha) nas parcelas, e os tempos de avaliação nas sub-parcelas $(7,30,60$ e 90 dias após o plantio das mudas).

Utilizou-se mudas de café provenientes de sacolas plásticas, com quatro a cinco pares de folhas desenvolvidas. As plantas de milho foram colhidas em campo, no estádio fenológico 4 (emissão do pendão), de acordo com FANCELLI e DOURADO NETO (2004). A parte aérea foi picada em máquina de forragem e seca em estufa de circulação forçada de $\operatorname{ar}\left(50^{\circ} \mathrm{C}\right)$ até peso constante do material.

Cada parcela constituiu-se de uma muda de café, plantada em vaso com capacidade de $7 \mathrm{~L}$ de solo. O substrato usado foi terra de subsolo, visando evitar contaminação por exsudados de raízes e lixiviados de folhas. As características físicas, químicas e classe textural do solo utilizado se encontram na Tabela 1. Foi aplicado calcário dolomítico (CaO: 28\%, MgO: 20\% e PRNT: $95 \%$ ) dois meses antes do plantio, afim de elevar a saturação por bases à 60\% (GUIMARÃES et al., 1999)

TABELA 1 - Resultados das análises física e química e classe textural do solo utilizado como substrato. UFLA, Lavras (MG).

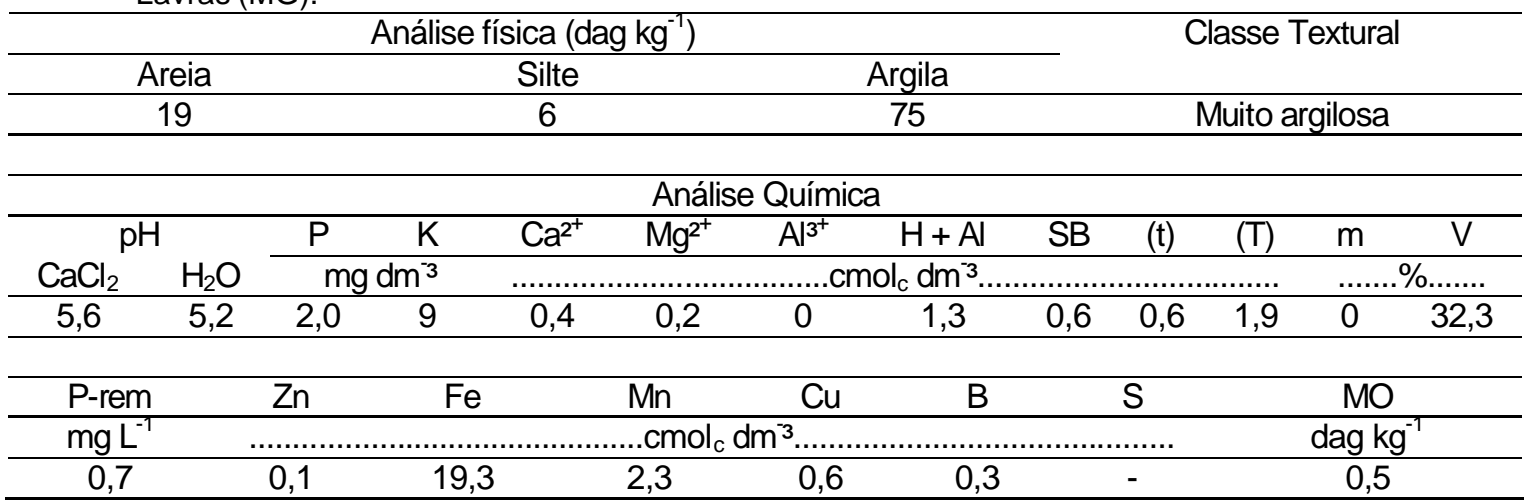


FRANÇA, A.C. et al. Efeitos de restos culturais de milho...

Aos vasos adicionaram-se $\mathrm{P}_{2} \mathrm{O}_{5}$ e $\mathrm{K}_{2} \mathrm{O}$ em quantidade recomendada para adubação de plantio em cova (GUIMARÃES et al., 1999). A palhada, seca e picada de cada híbrido de milho, foi incorporada na proporção de $8 \mathrm{t} \mathrm{ha}^{-1} \mathrm{em}$ toda a profundidade do vaso $(20 \mathrm{~cm})$ e devidamente homogeneizada no substrato. Em seguida, as mudas de café foram plantadas. As irrigações foram realizadas sempre que necessário, visando manter a umidade do solo próxima à capacidade de campo. Aos 30 dias após o plantio, realizou-se adubação foliar com ácido bórico e sulfato de zinco $0,1 \%(\mathrm{p} / \mathrm{v})$, mais $30 \mathrm{~g}$ de cloreto de potássio e $5 \mathrm{~g}$ de sulfato de amônio em cobertura por vaso (GUIMARÃES et al., 1999).

Para caracterizar a homogeneidade das mudas, realizou-se uma avaliação aos sete dias após o plantio (DAP). As seguintes determinações foram realizadas: altura das plantas, diâmetro do caule e área foliar, seguindo metodologia proposta por BARROS et al. (1973). Aos 30, 60 e 90 DAP foram avaliados a altura, o diâmetro do caule e a área foliar. Foram também realizadas leituras indiretas do teor de clorofila total das folhas do terço médio das plantas, através do clorofilômetro portátil SPAD-502, sendo realizada uma calibração prévia do clorofilômetro portátil utilizando espectrofotômetro para a quantificação do teor de clorofila, seguindo metodologia proposta por NETTO et al. (2005), e ajustando a seguinte equação: Ctotal ${ }_{(\mathrm{mg} \mathrm{mL}}{ }^{-1} \mathrm{y}=$ $0,915272+0,286493 x\left(R^{2}=96,23 \%\right)$, em que a variável independente $(X)$ representa as leituras realizadas pelo SPAD-502. Aos 90 DAP, as plantas foram removidas dos vasos e determinaram-se as biomassas secas de raízes, caules, folhas e calcularam-se as biomassas totais das plantas.

Os dados foram submetidos à análise de variância e as médias comparadas pelo teste ScottKnott ao nível de $5 \%$ de probabilidade.

\section{RESULTADOS E DISCUSSÃO}

Aos sete dias após o plantio das mudas de café (DAP), não foi verificada diferença entre os fatores analisados para a altura, o diâmetro do caule e a área foliar das mudas de café, mostrando homogeneidade entre elas (Tabela 2).

TABELA 2 - Resumo da análise de variância para altura, diâmetro do caule e área foliar de mudas de café dos cultivares Catucaí, Rubi, Topázio e Catuaí, submetidos a incorporações de palha de híbridos de milho (GNZ2004, GNZ2005, DKB350 e P30K75), aos 7 dias após o plantio (7 DAP). UFLA, Lavras (MG).

\begin{tabular}{lcccc}
\hline & \multicolumn{3}{c}{ Quadrado médio } \\
\hline FV & GL & Altura & Caule & Área Foliar $^{\text {GS }}$ \\
\hline Cultivares (C) & 3 & $0,345^{\text {ns }}$ & $0,002^{\text {ns }}$ & $0,050^{\text {ns }}$ \\
Incorporação (I) & 4 & $0,418^{\mathrm{ns}}$ & $0,003^{\mathrm{ns}}$ & $2,459^{\mathrm{ns}}$ \\
C X I & 12 & $0,158^{\mathrm{ns}}$ & $0,002^{\mathrm{ns}}$ & $1,474^{\mathrm{ns}}$ \\
Bloco & 3 & 0,437 & 0,001 & 0,386 \\
Erro & 57 & 0,273 & 0,002 & 1,735 \\
\hline Média & & 12,737 & 0,325 & 1,779 \\
\hline CV (\%) & 4,10 & 14,52 & 7,40 \\
\hline
\end{tabular}

$\mathrm{FV}=$ fontes de variação, $\mathrm{GL}=$ graus de liberdade, $\mathrm{CV}=$ coeficiente de variação. $^{\mathrm{ns}}$ - não significativo, a $5 \%$, pelo teste de F.

Aos 30 e 90 DAP, os cultivares de café comportaram de forma diferenciada quanto à altura média das plantas (Tabela 3). Aos 30 DAP, o cultivar Rubi apresentou a menor altura de plantas, com média de $14,8 \mathrm{~cm}$ e aos 90 DAP, Rubi e Topázio apresentaram as menores alturas $(30,7$ e $31,05 \mathrm{~cm}$, respectivamente), diferenciando-se dos cultivares Catucaí e Catuaí, que apresentaram médias de 31,73 e $31,55 \mathrm{~cm}$, respectivamente, independente da incorporação de palhas de milho. Os dados referentes à altura média das plantas de café neste experimento divergem daqueles obtidos por ALVES (2003), que observou que aos 100 DAP, em condições de campo, a incorporação de palhas de milho, foi dependente do tipo de híbrido de milho incorporado, onde os híbridos AG1051 e C333 reduziram a altura de plantas de café do cultivar Rubi, diferenciando do tratamento que não recebeu a palha. A área foliar dos cultivares de café não diferiram entre si aos 30 e 60 DAP. Aos 90 DAP, houve diferença entre os cultivares, destacando-se o Topázio, que apresentou maior área foliar com média de $11,03 \mathrm{dm}^{2}$, diferenciando-se do cultivar Catuaí, com 10,21 dm², e dos cultivares Rubi e Catucaí que não se diferenciaram entre si, com 9,07 e $8,78 \mathrm{dm}^{2}$, respectivamente. 
FRANÇA, A.C. et al. Efeito de restos culturais de milho...

TABELA 3 - Altura e área foliar de plantas de cultivares de café aos 30, 60 e 90 dias após o plantio (DAP). UFLA, Lavras (MG).

\begin{tabular}{lccc}
\hline \multicolumn{1}{c}{ Cultivares } & \multicolumn{3}{c}{ Altura $(\mathrm{cm})$} \\
\cline { 2 - 4 } & $30 \mathrm{DAP}$ & $60 \mathrm{DAP}$ & $90 \mathrm{DAP}$ \\
\hline Rubi & $14,80 \mathrm{~b}$ & $21,43 \mathrm{a}$ & $30,70 \mathrm{~b}$ \\
Catucaí & $16,07 \mathrm{a}$ & $21,98 \mathrm{a}$ & $31,73 \mathrm{a}$ \\
Topázio & $16,13 \mathrm{a}$ & $21,73 \mathrm{a}$ & $31,05 \mathrm{~b}$ \\
Catuaí & $15,83 \mathrm{a}$ & $22,22 \mathrm{a}$ & $31,55 \mathrm{a}$ \\
\hline & & Área foliar $\left(\mathrm{dm}^{2}\right)$ & $9,07 \mathrm{c}$ \\
\hline Rubi & $2,73 \mathrm{a}$ & $5,15 \mathrm{a}$ & $8,78 \mathrm{c}$ \\
Catucaí & $2,93 \mathrm{a}$ & $5,38 \mathrm{a}$ & $11,03 \mathrm{a}$ \\
Topázio & $3,13 \mathrm{a}$ & $5,79 \mathrm{a}$ & $10,21 \mathrm{~b}$ \\
Catuaí & $2,86 \mathrm{a}$ & $5,55 \mathrm{a}$ &
\end{tabular}

Médias seguidas da mesma letra na coluna não diferem entre si pelo teste Scott-Knott a 5\% de probabilidade.

Em relação ao efeito da incorporação do milho nas diferentes épocas de avaliação (Tabela 4), verificou-se que aos 90 DAP, a área foliar das plantas de café que não receberam palhas incorporadas, obtiveram as menores médias, tendo diferido significativamente dos demais tratamentos que receberam incorporações dos híbridos de milho. O híbrido GNZ 2004 quando incorporado causou aumento de $18,77 \%$ na área foliar em relação ao tratamento sem palha. Entretanto, SANTOS et al. (2003) constataram que a palhada de milho incorporada ao solo causou redução de $20,6 \%$ na área foliar acumulada em relação à testemunha, até 60 DAP.

TABELA 4 - Área foliar e teor de clorofila total de plantas de café, em função dos híbridos de milho incorporados aos 30, 60 e 90 dias após o plantio. UFLA (MG).

\begin{tabular}{lccc}
\hline \multirow{2}{*}{ Incorporação } & \multicolumn{3}{c}{ Área foliar $\left(\mathrm{dm}^{2}\right)$} \\
\cline { 2 - 4 } & 30 & 60 & 90 \\
\hline GNZ 2005 & $2,82 \mathrm{a}$ & $5,53 \mathrm{a}$ & $9,70 \mathrm{~b}$ \\
DKB 350 & $2,82 \mathrm{a}$ & $5,20 \mathrm{a}$ & $9,75 \mathrm{~b}$ \\
GNZ 2004 & $2,90 \mathrm{a}$ & $5,75 \mathrm{a}$ & $10,87 \mathrm{a}$ \\
P30K75 & $2,93 \mathrm{a}$ & $5,75 \mathrm{a}$ & $9,71 \mathrm{~b}$ \\
Testemunha & $2,99 \mathrm{a}$ & $5,11 \mathrm{a}$ & $8,83 \mathrm{c}$ \\
\hline \multicolumn{4}{c}{ Clorofila total $\left(\mathrm{mg} \mathrm{mL}^{-1}\right)$} \\
\hline GNZ 2005 & $12,50 \mathrm{~b}$ & $13,70 \mathrm{~b}$ & $14,96 \mathrm{a}$ \\
DKB 350 & $12,41 \mathrm{~b}$ & $14,33 \mathrm{~b}$ & $15,02 \mathrm{a}$ \\
GNZ 2004 & $12,28 \mathrm{~b}$ & $15,27 \mathrm{a}$ & $15,27 \mathrm{a}$ \\
P30K75 & $12,03 \mathrm{~b}$ & $14,34 \mathrm{~b}$ & $14,46 \mathrm{a}$ \\
Testemunha & $13,01 \mathrm{a}$ & $14,52 \mathrm{~b}$ \\
\hline Médias seguidas da mesma letra nas colunas não diferem entre si pelo teste Scott-Knott a 5\% \\
de probabilidade.
\end{tabular}

Aos 90 DAP, observou-se incremento no desenvolvimento da área foliar dos cafeeiros que receberam palhas incorporadas, devido, possivelmente a maior retenção da umidade do solo e liberação de nitrogênio resultante da decomposição da palhada (RICE, 1984). CALONEGO et al. (2005) e ROSOLEM et al. (2005) demonstraram que à medida que as plantas de milheto dessecadas senescem e recebem chuvas, elas liberam potássio, que é retornado ao solo, favorecendo as culturas instaladas. Este efeito benéfico das incorporações de palhas em relação a não incorporação pode ser também devido à liberação de maiores quantidades de aleloquímicos na fase inicial de decomposição da palha, que com passar do tempo foram degradados, perdendo seu efeito inibitório. Quando os aleloquímicos estão em pequenas concentrações no solo, podem também ocasionar efeitos benéficos (GUENZI e McCALLA, 1966; SANTOS et al., 2003). AL MEZORI et al. (1999) constataram que o efeito inibitório de palha de milho sobre o crescimento da parte aérea de plantas de milho persistiu por 6 semanas.

O teor de clorofila total das plantas de café (Tabela 4) foi afetado de forma diferenciada pela incorporação de palhas dos híbridos de milho. Aos 30 DAP, foi observado o maior teor de clorofila total na testemunha (sem palha), com média de $13,01 \mathrm{mg}$ $\mathrm{mL}^{-1}$, diferenciando dos demais tratamentos. Ressalta-se que, com a deposição de material vegetal no solo, para aqueles com alta relação $\mathrm{C} / \mathrm{N}$, como é o caso da planta de milho, o nitrogênio mineral do 
solo é imobilizado pelos microrganismos que dele necessitam para a síntese de seus compostos celulares, chegando a desaparecer do solo durante o período de crescimento máximo da comunidade microbiana, que coincide com o início da decomposição (CARDOSO, 1992). Neste período, dependendo das exigências nutricionais da espécie, esta pode ter deficiência de nitrogênio nas folhas que comprometerão à síntese de clorofila (CORREIA et al., 2006), já que 50 à $70 \%$ do nitrogênio total das folhas é integrante de enzimas associadas aos cloroplastos (CHAPMAN e BARRETO, 1997). Aos 60 DAP, verificou-se que a incorporação de palha do híbrido GNZ2004 promoveu maior teor de clorofila nas folhas das plantas de café, superando o tratamento sem palha incorporada em $5,15 \%$; e aos 90 DAP não verificou-se efeito da incorporação dos híbridos de milho, não havendo diferenças em relação à testemunha. Este resultado pode ser explicado em virtude de representar a fase de declínio da comunidade microbiana, onde o nitrogênio mineral volta a ser disponibilizado às plantas de café (CARDOSO, 1992). SANTOS et al. (2003) concluíram que as incorporações de palhas de híbridos de milho não influenciaram o teor de clorofila de plantas de café, cultivar Rubi, aos 170 DAP.

$\mathrm{Na}$ incorporação com o P30K75, os cultivares de café Catuaí e Catucaí obtiveram os maiores teores de clorofila total, com médias de 13,01 e 13,71 mg. $\mathrm{mL}^{-1}$, respectivamente (Figura 1 ). Quando a palha de milho não foi incorporada, o cultivar Topázio apresentou o menor teor de clorofila, diferenciando-se dos demais cultivares. Já a incorporação de GNZ2004, GNZ2005 e DKB350 não proporcionaram diferenças no teor de clorofila das folhas dos cultivares de café estudados.

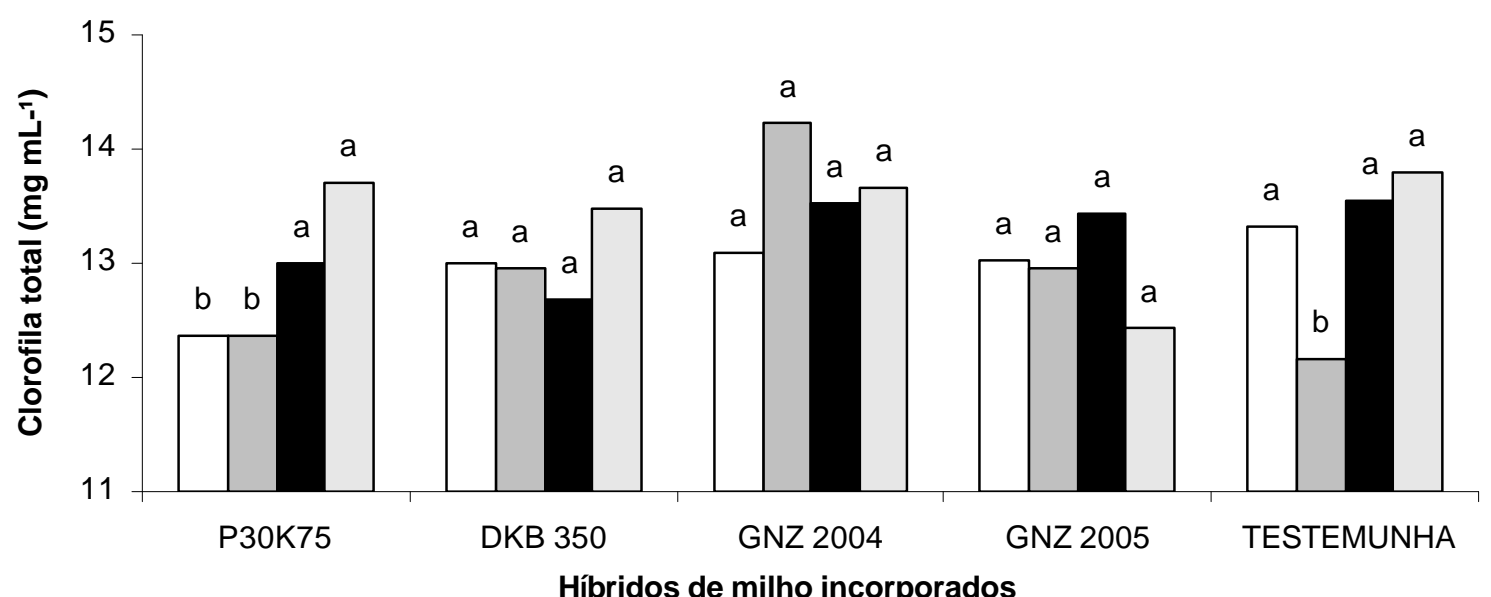

\section{$\square$ Rubi $\square$ Topázio $\square$ Catuaí $\square$ Catucaí}

FIGURA 1 - Teor de clorofila total de plantas de café, em função dos cultivares utilizados (Rubi, Topázio, Catuaí e Catucaí), dentro de cada híbrido de milho incorporado (P30K75, DKB350, GNZ2004, GNZ2005 e Teste - sem incorporação). UFLA (MG). Para cada híbrido incorporado, médias seguidas de mesma letra não diferem entre si pelo teste de Scott-Knott a 5\% de probabilidade.

Quando estudou-se os híbridos de milho incorporados dentro de cada cultivar de café, observou-se (Figura 2), que os teores de clorofila total dos cultivares Topázio e Catucaí foram dependentes do híbrido de milho incorporado. Para o cultivar Topázio, palha do híbrido GNZ2004 promoveu incremento de $17,07 \%$, enquanto que, para o cultivar Catucaí, a palha do GNZ2005 promoveu redução de $9,87 \%$ quando comparadas ao tratamento testemunha, mesmo não sendo observados quaisquer efeitos visuais de fitotoxicidade ou clorose das folhas nas plantas de café. De acordo com ALMEIDA (1991), o amarelecimento ou clorose das folhas é o sintoma mais citado na literatura de possíveis efeitos alelopáticos. Este efeito divergente entre as incorporações de palhas de híbridos de milho se deve às substâncias alelopáticas contidas nesta espécie. Do grupo químico dos fenólicos, o aleloquímico encontrado no milho em maior concentração é conhecido como benzoxazolinona, que é capaz de inibir a síntese de clorofila das plantas (SOUZA e EINHELLIG, 1994). Esta substância é sintetizada em concentrações diferentes nos híbridos de milho, sendo que ALVES (2003) identificou diferenças entre as concentrações de benzoxazolinona encontrada nas folhas, dos híbridos AG1051, C333 e C435 (29 $\mathrm{g} \mathrm{g} \mathrm{g}^{-1}, 24 \mu_{\mathrm{g} \mathrm{g}}^{-1} \mathrm{e} 21 \mu \mathrm{g} \mathrm{g}$ 1 de matéria fresca, respectivamente). O autor verificou que estes resultados afetaram de forma diferenciada o teor de clorofila de plantas de café 'Rubi'. 
FRANÇA, A.C. et al. Efeito de restos culturais de milho...

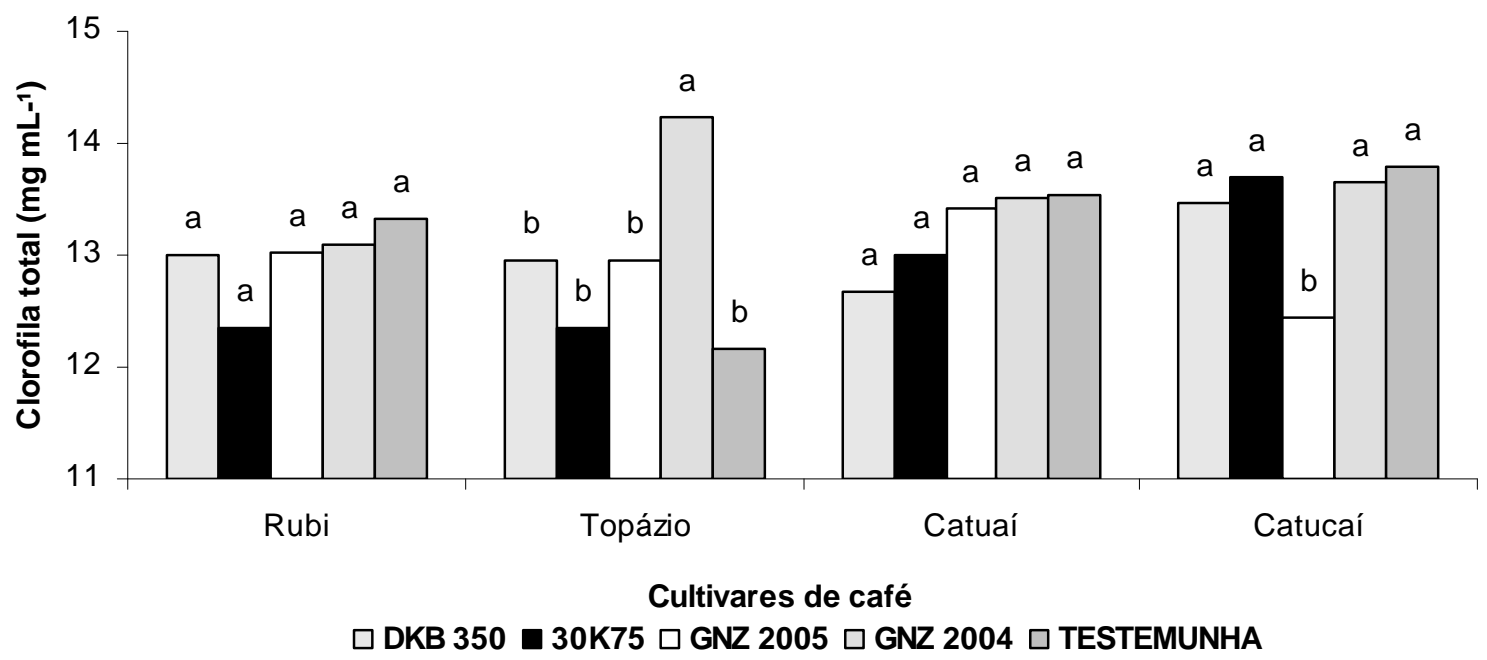

FIGURA 2 - Teor de clorofila total de plantas de café, em função dos híbridos de milho incorporados (P30K75, DKB350, GNZ2004, GNZ2005 e Teste - sem incorporação) dentro de cada cultivar utilizado (Rubi, Topázio, Catuaí e Catucaí) UFLA (MG). Para cada cultivar de café, médias seguidas de mesma letra não diferem entre si pelo teste de Scott-Knott a $5 \%$ de probabilidade.

A palha do híbrido GNZ2004 promoveu os maiores acúmulos de biomassa do caule nos cultivares Topázio e Catucaí, com médias de 3,60 e 2,99 g, respectivamente (Figura 3). A incorporação do híbrido GNZ2005 causou um menor acúmulo de biomassa no caule para o cultivar Catucaí, aos 90 DAP, diferenciando-se dos demais cultivares de cafeeiro.

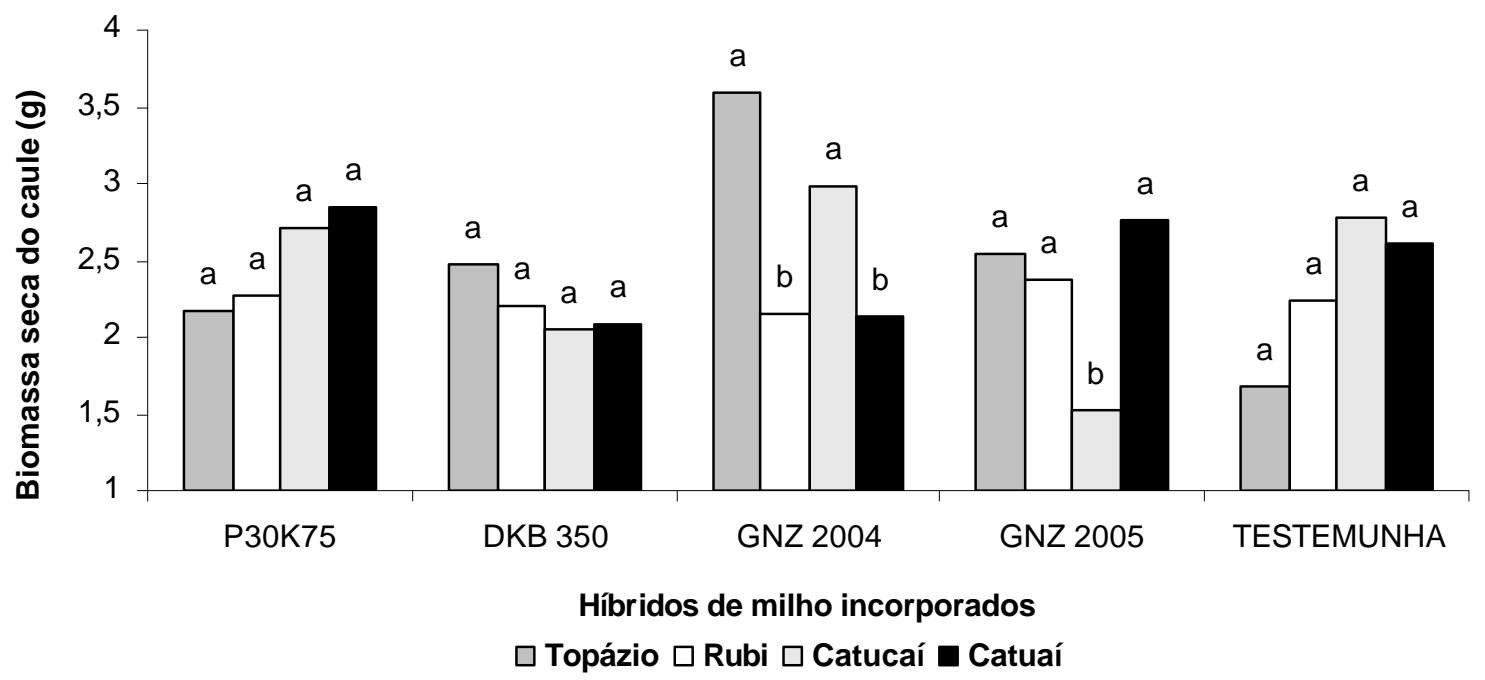

FIGURA 3 - Biomassa seca do caule de plantas de café, em função dos cultivares utilizados (Rubi, Topázio, Catuaí e Catucaí) dentro de cada híbrido de milho incorporado (P30K75, DKB350, GNZ2004, GNZ2005 e Teste - sem incorporação). UFLA (MG). Para cada híbrido incorporado, médias seguidas de mesma letra não diferem entre si pelo teste de Scott-Knott a $5 \%$ de probabilidade.

O cultivar Topázio obteve o maior acúmulo de biomassa do caule quando recebeu palha do híbrido de milho GNZ2004, diferenciando-se dos demais híbridos (Figura 4). Para o Catucaí, as incorporações de DKB350 e GNZ2005 promoveram os menores acúmulos de biomassa do caule. A influência do teor de clorofila exercido na inibição da incorporação de palha do híbrido GNZ2005 ao cultivar Catucaí; e incremento desta variável quando incorporou-se palha do híbrido GNZ2004 ao cultivar Topázio, refletiu-se na metabolização de assimilados ao caule do cafeeiro, que segue a mesma tendência verificada para o teor de clorofila. 


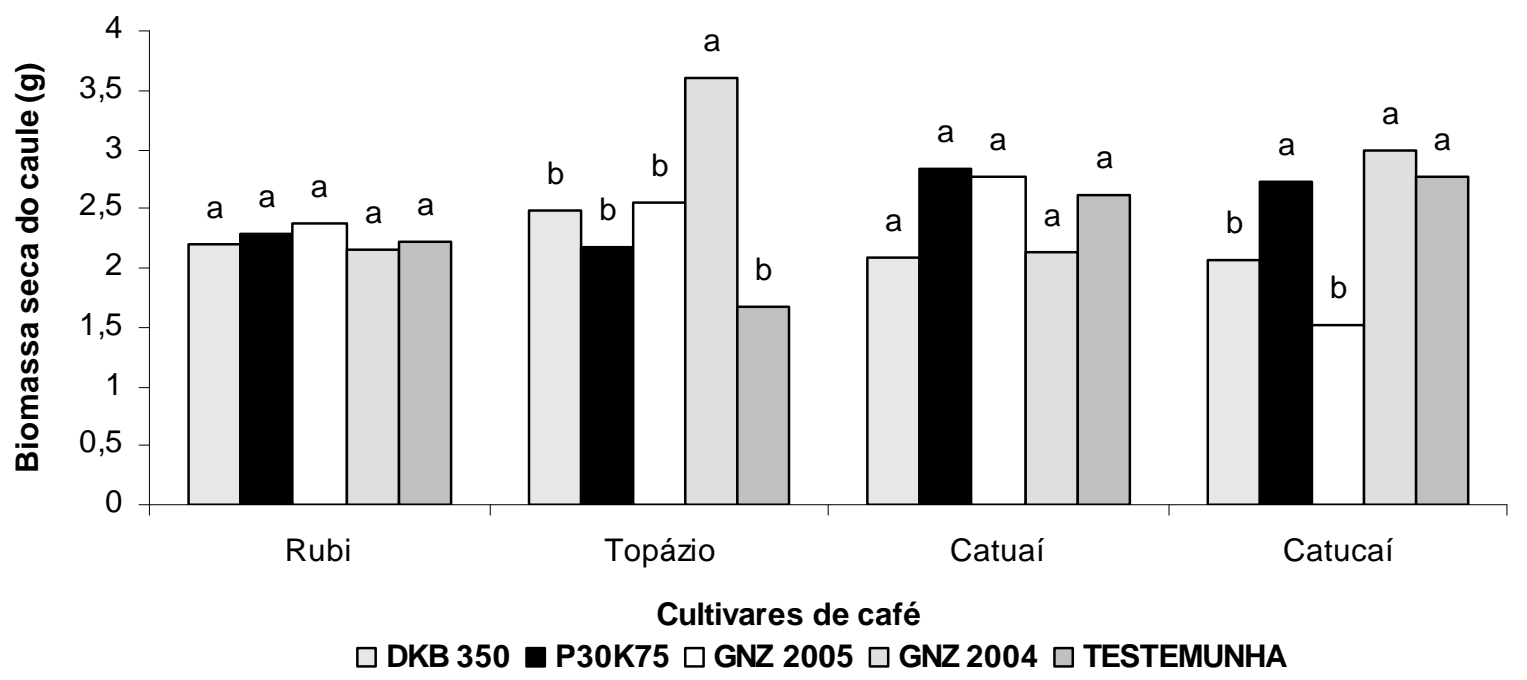

FIGURA 4 - Biomassa seca do caule de plantas de café, em função dos híbridos de milho incorporados (P30K75, DKB 350, GNZ 2004, GNZ 2005 e sem incorporação), dentro de cada cultivar de café utilizado (Rubi, Topázio, Catuaí e Catucaí). UFLA (MG). Para cada cultivar de café, médias seguidas de mesma letra não diferem entre si pelo teste de Scott-Knott a $5 \%$ de probabilidade.

Para a biomassa seca das folhas e biomassa total das plantas de café, não houve diferença significativa entre os fatores isolados e entre sua interação, aos 90 DAP (Tabela 5).

TABELA 5 - Resumo da análise de variância para peso da biomassa seca de caule, folha, raiz e total de plantas de café, em função dos cultivares utilizados (Catuaí, Catucaí, Rubi e Topázio) e dos híbridos de milho incorporados (GNZ 2004, GNZ 2005, P 30K75, DKB 350 e sem incorporação), aos 90 dias após o plantio (90 DAP). UFLA (MG).

\begin{tabular}{lccccc}
\hline & \multicolumn{5}{c}{ Quadrado médio } \\
\hline \multirow{2}{*}{ FV } & GL & Caule & Folha & Raiz & Total \\
\cline { 3 - 6 } & 3 & $0,265^{\text {ns }}$ & $2,102^{\text {ns }}$ & $2,213^{\text {ns }}$ & $7,362^{\text {ns }}$ \\
\hline Cultivares & 4 & $0,660^{\text {ns }}$ & $5,352^{\text {ns }}$ & $4,703^{*}$ & $7,660^{\text {ns }}$ \\
Incorporação & 12 & $1,119^{*}$ & $4,845^{\text {ns }}$ & $1,697^{\text {ns }}$ & $18,106^{\text {ns }}$ \\
Cultiv. X Inco. & 3 & 0,549 & 4,699 & 3,799 & 17,521 \\
Bloco & 57 & 0,402 & 2,881 & 1,239 & 9,619 \\
Erro & & 2,409 & 7,894 & 4,157 & 14,46 \\
\hline Média & & 26,32 & 21,50 & 26,79 & 21,45 \\
\hline CV (\%) & & &
\end{tabular}

$\mathrm{FV}=$ fontes de variação, $\mathrm{GL}=$ graus de liberdade, $\mathrm{CV}=$ coeficiente de variação.

${ }^{*}{ }^{\text {ns }}$ significativo e não significativo respectivamente, a $5 \%$, pelo teste $\mathrm{F}$.

Observou-se que aos 90 DAP, houve resposta às incorporações de palha dos híbridos de milho para biomassa seca de raízes de cafeeiro (Figura 5). As incorporações dos híbridos GNZ2004 e P30K75 proporcionaram respostas de 27,26 e $17,31 \%$ superior ao tratamento testemunha; entretanto a incorporação do híbrido DKB350 reduziu a biomassa seca das raízes em $8,96 \%$, mas não diferenciando da testemunha. Corroborando com estes resultados, SANTOS et al. (2003) verificaram que na proporção de $8 \mathrm{t} \mathrm{ha}^{-1}$, a palhada do híbrido AG1051 causou redução de $14 \%$ na biomassa seca de raízes, enquanto que para os híbridos C435 e C333 não foi observado redução, quando comparados com o tratamento sem palha. 
FRANÇA, A.C. et al. Efeito de restos culturais de milho...

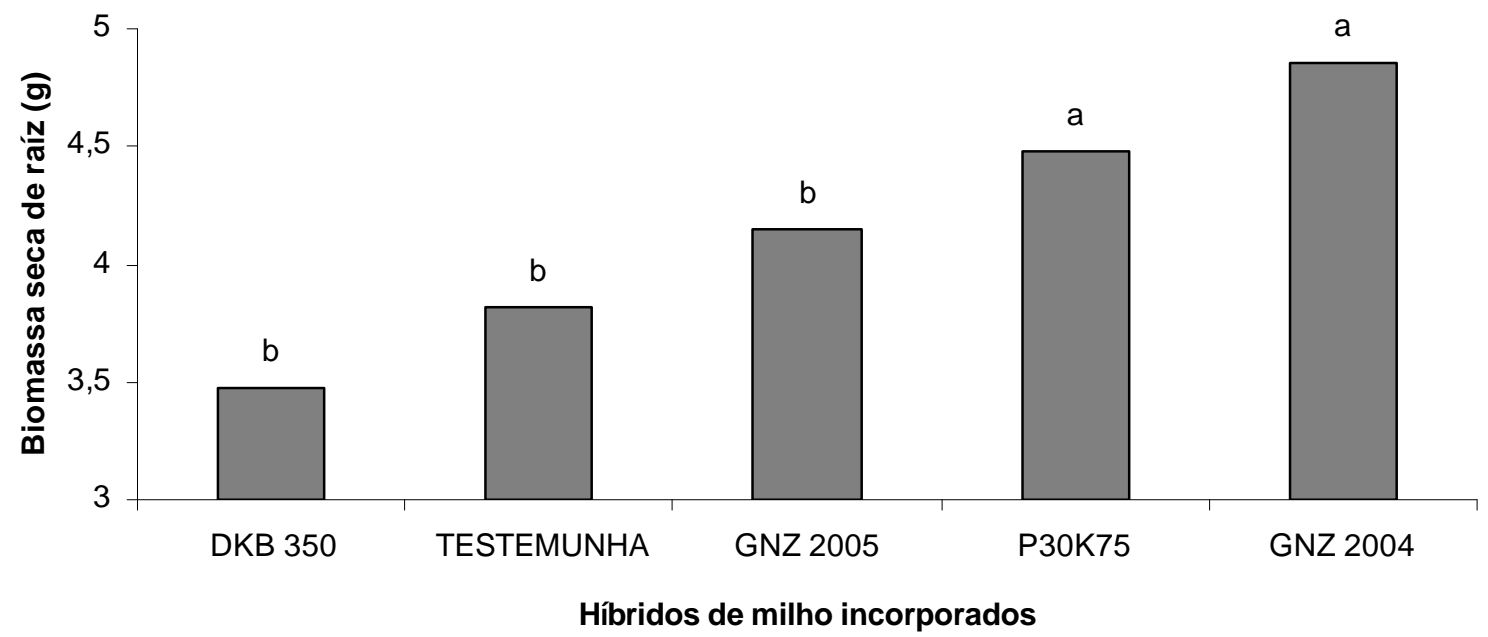

FIGURA 5 - Biomassa seca de raízes de plantas de café, em função dos híbridos de milho incorporados. UFLA (MG). Colunas com as mesmas letras são significativamente iguais entre si pelo teste Scott-Knott a $5 \%$ de probabilidade.

\section{CONCLUSÕES}

A incorporação de palha do híbrido GNZ 2004 favoreceu a área foliar e o teor de clorofila dos cultivares de café estudados (Catucaí, Catuaí, Topázio e Rubi) aos 90 e 60 DAP, respectivamente.

A palhada do híbrido GNZ2004 favoreceu o teor de clorofila total nas folhas e o acúmulo de biomassa do caule do cultivar Topázio, entretanto para estas variáveis, a palhada do GNZ2005 causou efeito detrimental para o cultivar Catucaí.

A incorporação de palhas dos híbridos de milho GNZ2004 e P30K75 favoreceram o acúmulo de biomassa seca de raízes de café dos cultivares Catucaí, Catuaí, Topázio e Rubi.

\section{AGRADECIMENTO}

À Fundação de Amparo à Pesquisa do Estado de Minas Gerais (FAPEMIG), pela liberação dos recursos destinados a esta pesquisa.

\section{REFERÊNCIAS}

1. AGRIANUAL 2006. Anuário da Agricultura Brasileira. São Paulo: FNP Consultoria e Comércio, 2006.

2. ALMEIDA, F.S. Efeitos alelopáticos de resíduos vegetais. Pesquisa Agropecuária Brasileira, v. 26, n. 2, p. 221-236, 1991.

3. AL MEZORI, H.A.; AL-SAADAWI, I.S.; AL-HADITHI, T.R. Allelopathic effects of corn residues on the subsequent corn crop. Allelopathy Journal, v. 6, n. 2, p. 193-200, 1999.

4. ALVES, L.W.R. Interferência alelopática da cultura do milho (Zea mays L.) sobre a cultura do cafeeiro (Coffea arabica L.) plantada em sucessão. Lavras, 2003. 89 f. Tese (Doutorado em Fitotecnia) - Universidade Federal de Lavras.

5. BANZATTO, D.A.; KRONKA, S.N. Experimentação agrícola. 4 ed. Jaboticabal: FUNEP, 2006. 237 p.

6. BARROS, R.S.; MESTRI, M.; VIEIRA, M.; BRAGA FILHO, L.J. Determinação de área de folhas do café (Coffea arabica cv. Bourbon Amarelo). Revista Ceres, v. 20, n. 107, p. 44-52, 1973.

7. CALONEGO, J.C.; FOLONI, J.S.S.; ROSOLEM, C.A. Lixiviação de potássio da palha de cobertura em diferentes estádios de senescência a dessecação química. Revista Brasileira da Ciência do Solo, v. 29, n. 1, p. 99-108, 2005.

8. CARDOSO, E.J.B.N. Efeito da matéria orgânica na biologia do solo. In: GUERRINI, I.A.; THEODORO, L. (Eds.). ENCONTRO SOBRE A MATÉRIA ORGÂNICA DO SOLO: PROBLEMAS E SOLUÇÕES, 1992, Botucatu. Anais. Botucatu: FCA/UNESP, 1992. p. 37-62.

9. CHAPMAN, S.C.; BARRETO, H.J. Using a chlorophyll meter to estimate specific leaf nitrogen of tropical maize during vegetative growth. Agronomy Journal, v. 89, n. 4, p. 557-562, 1997.

10. CORREIA, N.M.; DURIGAN, J.C.; KLINK, U.P. Influência do tipo e da quantidade de resíduos vegetais na emergência de plantas daninhas. Planta Daninha, v. 24, n. 2, p. 245-253, 2006.

11. DURIGAN, J.C.; ALMEIDA, F.L.S. Noções sobre alelopatia. Jaboticabal: FUNEP, 1993. 28 p.

12. FANCELLI, A.L.; DOURADO NETO, D. Produção de milho. 2. ed. Guaíba: Agropecuária, 2004. 360 p.

13. FERREIRA, A.G.; AQUILA, M.E.A. Alelopatia: Uma área emergente da ecofisiologia vegetal. Revista Brasileira de Fisiologia Vegetal, v. 12, n. 1, p. 175-204, 2000.

14. GUENZI, W.D.; McCALLA, T.M. Phenolic acids in oats, wheat, sorghum and corn residues and their phytotoxicity. Agronomy Journal, v. 58, n. 3, p. 303-304, 1966.

15. GUIMARÃES, P.T.G.; GARCIA, A.V.R.; ALVAREZ V.H.; PREZOTTI, L.C.; VIANA, A.S.; MIGUEL, A.E.; MALAVOLTA, E.; CORREAA, J.B.; LOPES, A.S.; NOGUEIRA, F.D.; MONTEIRO, A.V.C.; OLIVEIRA, J.A. Cafeeiro. In: COMISSÃO DE 
FRANÇA, A.C. et al. Efeitos de restos culturais de milho...

FERTILIDADE DO SOLO DO ESTADO DE MINAS GERAIS. Recomendações para uso de corretivos e fertilizantes em Minas Gerais: $5^{\mathrm{a}}$ aproximação. Viçosa, 1999. p. 289-302.

16. NETTO, A.T.; CAMPOSTRINI, E.; OLIVEIRA, J.G.; BRESSAN-SMITH, R.E. Photosynthetic pigments, nitrogen, chlorophyll a fluorescence and SPAD-502 readings in coffee leaves. Scientia Horticulturae, v. 104, n. 2, p. 199-209, 2005.

17. OLIBONE, D.; CALONEGO, J.C.; PAVINATO, P.S.; ROSOLEM, C.A. Crescimento inicial da soja sob efeito de resíduos de sorgo. Planta Daninha, v. 24, n. 2, p. 255-261, 2006.

18. PAES, J.M.V.; ZITO, R.K. Manejo de plantas daninhas na cultura do milho. Informe Agropecuário, v. 27, n. 233, p. 54-64, 2006.

19. RICE, E.L. Allelopathy. 2. ed. Orlando: Academic Press, 1984. 422 p.

20. ROSOLEM, C.A.; COLONEGO, J.C.; FOLONI, J.S. Potassium leaching from millet straw as affected by rainfall and potassium rates. Communication Soil Science Plant Analysis, v. 36, n. 7-8, p. 1063-1074, 2005.

21. SANTOS, C.C. Efeito de resíduos de milho sobre o desenvolvimento de cafeeiros (Coffea arabica L.). Lavras, 2002. 62 f. Dissertação (Mestrado em Fitotecnia) - Universidade Federal de Lavras.

22. SANTOS, C.C.; SOUZA, I.F.; ALVES, L.W.R. Efeitos de restos de culturas de milho sobre o crescimento de plantas de cafeeiro (Coffea arabica L.). Ciência e Agrotecnologia, v. 27, n. 5, p. 991-1001, 2003.

23. SOUZA, I.F.; EINHELLIG, M.F.A. Potencial alelopático de 2-benzoxazolinona (BOA) e sua interação com atrazine no crescimento de plantas. Planta Daninha, v. 12, n. 2, p. 84-86, 1994.

24. SOUZA, L.S.; FAVORETO, A.F.; FERRAZ, R.A.; VELINI, E.D. Efeitos alelopáticos de capim braquiária (Brachiaria decumbens) sobre três cultivares de café (Coffea arabica). In: CONGRESSO BRASILEIRO DA CIÊNCIA DAS PLANTAS DANINHAS, 22., 2000, Foz do Iguaçu. Resumos. Londrina: SBCPD, 2000. p. 84.

Recebido em 13/03/2007

Aceito em 11/07/2007 
